\title{
Analisis Pengaruh Lokasi Central Business District Terhadap Nilai Tanah di Daerah Sekitarnya (Studi Kasus: Daerah Industri di Surabaya)
}

\author{
Heri Yuli Safitri, Yanto Budisusanto, Udiana Wahyu, Andy Dediyono \\ Jurusan Teknik Geomatika, Fakultas Teknik Sipil dan Perencanaan, Institut Teknologi Sepuluh Nopember (ITS) \\ Jl. Arief Rahman Hakim, Surabaya 60111 Indonesia \\ e-mail:yanto_budisusanto@yahoo.com,udiana@geodesy.its.ac.id, andy.dediyono@gmail.com, \\ ichahys.30@gmail.com
}

\begin{abstract}
Abstrak-Kota Surabaya mengalami suatu perkembangan yang sangat pesat dibandingkan dengan pertumbuhan kota-kota disekitarnya. Perkembangan penduduk kota Surabaya yang mempunyai predikat kota Industri, Dagang, Maritim dan Pendidikan berjalan sangat pesat. Akibatnya, nilai tanah pada lokasi tertentu yang mempunyai kemudahan mencapai sarana kegiatan tersebut akan mengalami kenaikan tingkat harga nilai tanah. Untuk mengetahui pengaruh Pusat Kegiatan Kota/Central Business District (CBD) terhadap nilai tanah, digunakan metode analisis yang meliputi analisis spasial dengan metode penaksiran harga tanah Von thunen (Teori Lokasi) yang akan menunjukkan pengaruh jarak ke CBD dan persebaran letak NIR tertinggi sampai terendahnya. Serta analisis faktor penentu nilai tanah tersebut dengan NIR yang menggunakan metode perbandingan Pendekatan Data Pasar (Market Data Approach) dalam setiap zona yang telah dibuat. Hasil dari analisis yang telah dilakukan menunjukkan bahwa CBD Industri memiliki NIR tertinggi sebesar Rp 11.732.291,-. Dan dari hasil analisis klasifikasi NIR pada daerah sekitar CBD SIER yang dilakukan sejauh 3 kilometer mempunyai kecenderungan nilai tanah yang semakin tinggi jika menjauh dari CBD. Selain faktor jarak terhadap CBD, faktor kedudukan tanah terhadap jalan juga sangat mempengaruhi nilai tanah tersebut.
\end{abstract}

Kata Kunci-Central Business District(CBD), Industri, Nilai Indikasi Rata-Rata (NIR), Nilai Tanah

\section{PENDAHULUAN}

$\mathrm{K}$ OTA surabaya mengalami suatu perkembangan yang sangat pesat dibandingkan dengan pertumbuhan kota-kota disekitarnya. Perkembangan penduduk kota Surabaya yang mempunyai predikat kota Industri, Dagang, Maritim dan Pendidikan berjalan sangat pesat. Akibatnya, nilai tanah pada lokasi tertentu yang mempunyai kemudahan mencapai sarana kegiatan tersebut akan mengalami kenaikan tingkat harga nilai tanah [1].

Nilai tanah dipengaruhi oleh beberapa faktor, salah satu dari faktor yang mendukung adalah faktor lokasi. Lokasi dapat diuraikan dengan atribut aksesibilitas dan lingkungan [2]. Dalam prinsip dasar Teori Lokasi menurut Von thunen (1826) menyatakan bahwa harga tanah ditentukan oleh panjang jarak geografi lokasi tanah tersebut ke/dari pusat kegiatan kota/Central Business Distric(CBD). Pusat kota atau CBD dalam pemahaman Von thunen adalah pasar (market), yang mencerminkan pusat kegiatan ekonomi [3].

Metode analisis yang digunakan meliputi analisis spasial dengan metode penaksiran harga tanah Von thunen (Teori Lokasi) yang akan menunjukkan pengaruh jarak ke CBD dan persebaran letak NIR tertinggi sampai terendahnya. Serta analisis faktor penentu nilai tanah tersebut dengan NIR yang didapat dengan metode perbandingan Pendekatan Data Pasar (Market Data Approach) dalam setiap zona yang telah dibuat.

Dengan tugas akhir ini diharapkan alih fungsi lahan yang berada di daerah sekitar CBD Industri yang diwakilkan oleh daerah Surabaya Industrial Estate Rungkut (SIER) dapat dikontrol nilai tanahnya. Dengan penelitian ini, dapat diketahui juga perkembangan nilai tanah agar perubahan nilai tanah tetap terkontrol sesuai dengan perencanaan pembangunan dan rencana tata ruang kota Surabaya.

\section{METODOLOGI PENELITIAN}

\section{A. Lokasi Penelitian}

Lokasi penelitian Tugas Akhir ini mengambil studi di daerah Surabaya yang secara geografis terletak pada koordinat $07^{\circ} 09^{\circ}-07^{\circ} 21^{`}$ Lintang Selatan dan $112^{\circ} 36^{\prime}-112^{\circ} 54^{`}$ Bujur Timur yang bisa dilihat pada Gambar 1 . 


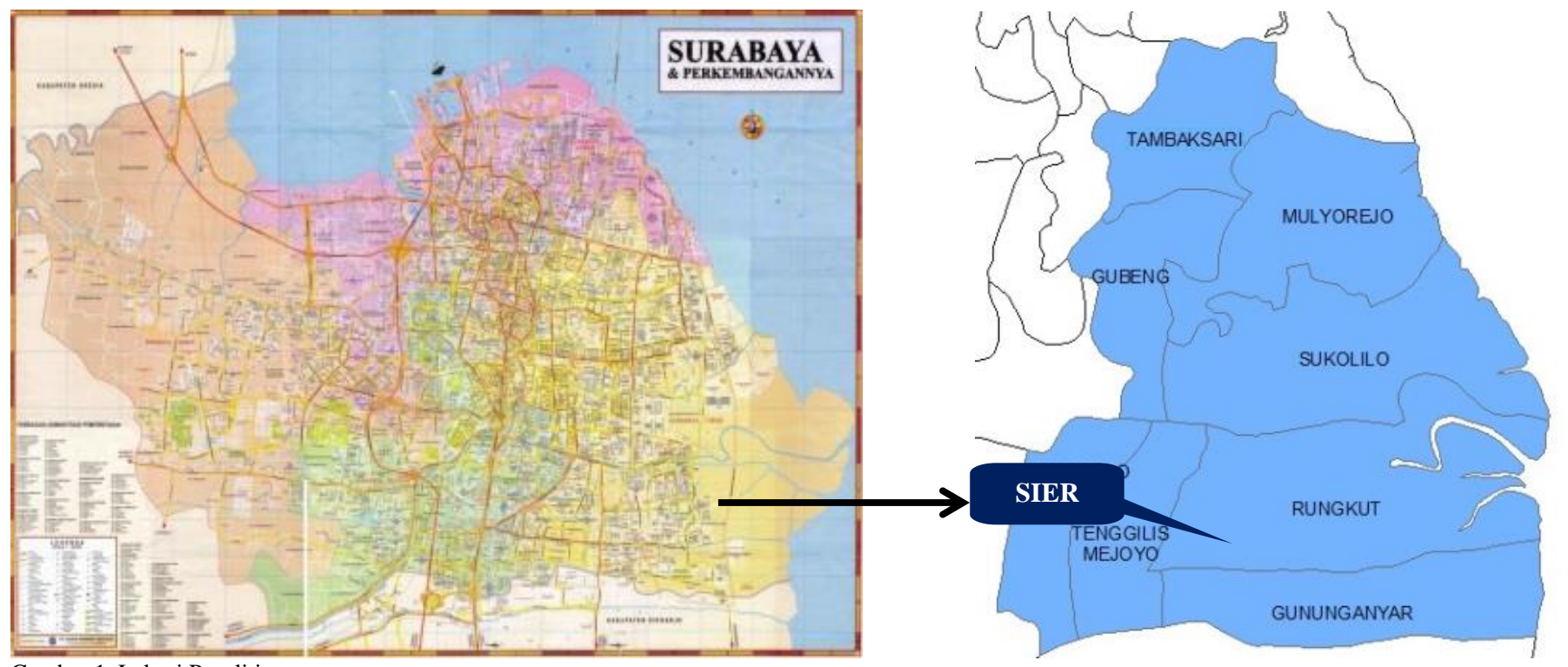

Gambar 1. Lokasi Penelitian

(Sumber : Pemerintah Kota Surabaya)

Daerah sekitar CBD yang digunakan pada penelitian kali ini, yaitu daerah sekitar CBD SIER yang menjadi lokasi penelitian tersebar di 5 kecamatan, yaitu kecamatan Sukolilo, kecamatan Rungkut, kecamatan Gunung Anyar, kecamatan Tenggilis Mejoyo dan kecamatan Wonocolo.

\section{B. Metodologi Penelitian}

Pada penelitian ini dilakukan beberapa tahapan pelaksanaan penelitian, yaitu:

1) Identifikasi Masalah

Kegiatan ini menentukan permasalahan yang akan diselesaikan, yaitu pembuatan peta klasifikasi nilai tanah pada daerah sekitar CBD Surabaya Industrial Estate Rungkut (SIER) dan analisis pengaruh CBD tersebut terhadap nilai tanah di daerah sekitarnya.

\section{2) Studi Literatur}

Kegiatan ini dilakukan untuk mencari informasi dan mendapatkan referensi yang menunjang kegiatan penelitian, dapat berupa teori, rumus atau data dari buku, jurnal, majalah, internet ataupun dari sumber lainnya.

3) Pengumpulan Data

Kegiatan ini dilakukan untuk memperoleh data primer dan data sekunder. Data primer yang berupa data informasi harga tanah dan koordinat titik lokasi bidang tersebut yang didapatkan dari hasil survei lapangan dan data sekunder yang berupa peta administrasi dan peta citra yang sudah terkoreksi yang didapatkan dari Bappeko Surabaya.

4) Identifikasi Kawasan Sekitar CBD

Lokasi yang digunakan pada penelitian ini berada di daerah sekitar industri SIER yang berlokasi di 5 kecamatan dan 16 kelurahan. Titik yang digunakan sebagai titik pusat pada SIER terletak di titik tengah lokasi industri SIER.

5) Deliniasi Zona dengan Metoda Von thunen

Kegiatan ini digunakan untuk perencanaan survei lapangan dalam pengambilan titik sampel di lapangan. Metoda von thunen mempunyai tata cara dalam pengambilan sampel di lapangan. Dengan merencanakan pola perletakkan titik-titik sampel yang akan disurvei dengan membentuk jari-jari roda sepeda yang semuanya berpusat kepada "titik" pusat as roda (Pusat Kota/CBD) dan jika memungkinkan dibuat menurut delapan arah mata angin.

6) Analisis Perhitungan Nilai Tanah

Dalam perhitungan nilai tanah ini digunakan metode Perbandingan Pendekatan Data Pasar (Market Data Approach). Nilai tanah ini didapatkan dari data hasil survei Informasi Harga Tanah yang dianalisis, data informasi harga tanah yang didapatkan dari survei lapangan tidak dapat digunakan secara langsung, untuk mendapatkan nilai tanah tersebut harus dilakukan proses penyesuaian sehingga nilai yang didapatkan akurat.

\section{7) Deliniasi Zona Baru}

Data hasil perhitungan nilai tanah yang telah dilakukan proses penyesuaian di-plot pada peta kerja yang berisikan batas zona dengan metode von thunen, ternyata deliniasi zona tersebut tidak sesuai dengan prinsip pembuatan batas imajiner ZNT, maka diperlukan pembuatan batas imajiner zona baru dari hasil data nilai tanah. Pembuatan zona baru ini berdasarkan pada prinsip pembuatan batas imajiner ZNT pada Surat Edaran Direktur Jenderal Pajak nomor SE-25/PJ.6/2006 yang mengelompokan bidang tanah dalam satu ZNT dengan mempertimbangkan hal-hal sebagai berikut [4]:

a) Indikasi nilai tanah yang mirip

b) Memiliki karakteritik yang mirip, antara lain:

- Aksesibilitas, yang pada penelitian ini dibatasi pada jalan arteri primer dan arteri sekunder.

- Peruntukan tanah (zoning).

8) Analisis Perhitungan Nilai Indikasi Rata-Rata (NIR)

Setelah mendapatkan nilai tanah dan zonasi yang sudah sesuai, maka penentuan Nilai Indikasi Rata-rata (NIR) dilakukan dengan cara menjumlahkan minimal 3 data nilai tanah tersebut dan diambil rata-rata sehingga mendapatkan NIR pada masing-masing zona.

Setelah dilakukan deliniasi zona baru, terdapat beberapa zona yang tidak memiliki data harga jual, maka untuk ZNT tersebut, penentuan NIR dilakukan dengan cara memakai data 
pembanding dari zona yang ada, data yang pakai sebagai pembanding minimal 3 zona (ZNT). Dan setelah mendapatkan Nilai Indikasi Rata-rata (NIR) pada setiap zona, lakukan analisis antara NIR di zona yang satu dengan yang lainnya dalam setiap radius kilometernya.

9) Analisis Klasifikasi NIR

Kegiatan ini dilakukan untuk penarikan kesimpulan mengenai bagaimana pengaruh CBD SIER terhadap nilai tanah di daerah sekitarnya.

10) Hasil Penelitian

Hasil akhir dari penelitian ini merupakan Peta Klasifikasi Nilai Tanah di daerah sekitar CBD SIER dan menganalisis klasifikasi NIR pada setiap radius per kilometernya di daerah sekitar CBD tersebut.

\section{HASIL DAN ANALISA}

\section{A. Hasil Deliniasi Zona Metode Von thunen}

Pembuatan zona pada masing-masing daerah sekitar CBD dibuat sejauh radius 3 kilometer dari pusat lokasi CBD dan dibagi menjadi 8 zona yang mengikuti arah mata angin yang dibagi pada setiap radius 1 kilometer. Sehingga pada awal perencanaan survei lapangan pada daerah sekitar CBD SIER terdiri dari 21 zona yang lokasinya tersebar seperti pada Gambar 2.

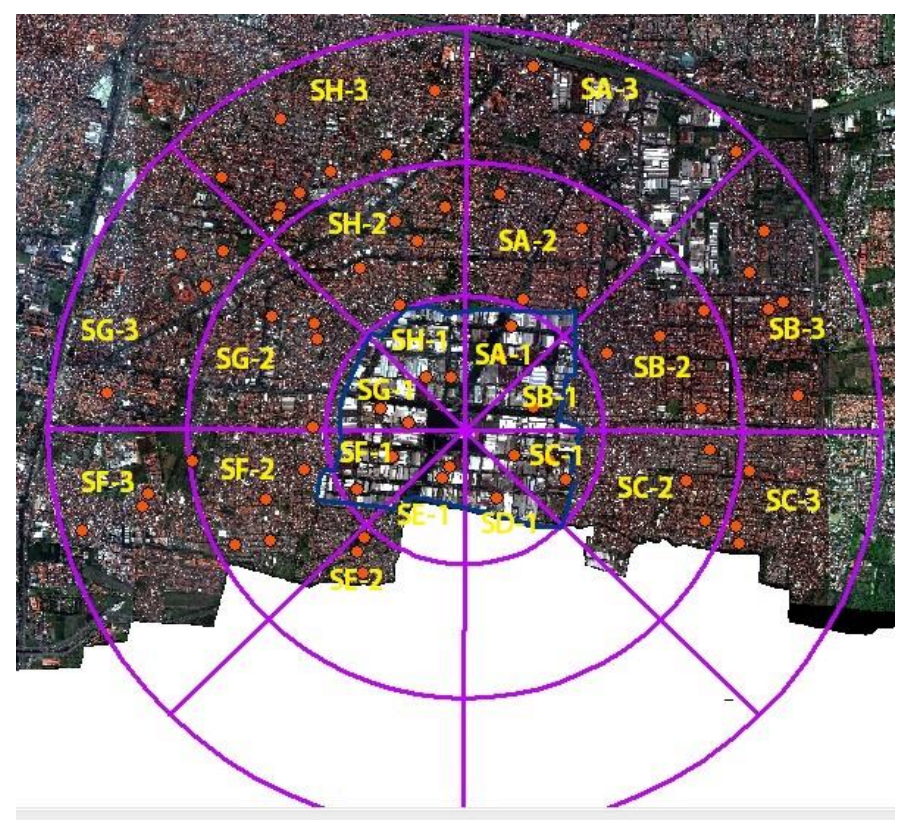

Gambar 2. Hasil deliniasi zona dengan Metode Von thunen daerah sekitar CBD SIER.

(Sumber : Hasil Pengolahan Data)

\section{B. Perhitungan Nilai Tanah}

Data informasi harga tanah yang didapatkan dari survei lapangan tidak dapat digunakan secara langsung, untuk mendapatkan nilai tanah tersebut harus dilakukan proses penyesuaian sehingga nilai yang didapatkan akurat. Penyesuaian dilakukan dengan mempertimbangkan pengaruhpengaruh yang ada pada atributik data tersebut. Beberapa hasil dari perhitungan nilai tanah yang sudah dilakukan dapat di lihat pada Tabel 1.

Tabel 1.

\begin{tabular}{clc}
\multicolumn{3}{c}{ Hasil Perhitungan Nilai Tanah daerah sekitar CBD SIER } \\
\hline No & Kode Titik & Indikasi Nilai Pasar Tanah / m ${ }^{2}$ \\
\hline 1 & SA3-T4 & Rp9,188,538 \\
2 & SH3b-T5 & Rp7,064,557 \\
3 & SA3-T6 & Rp6,682,967 \\
4 & SH3b-T2 & Rp11,536,850 \\
5 & SH3b-T1 & Rp11,794,474 \\
6 & SH3b-T3 & Rp11,794,474 \\
7 & SA3-T1 & Rp6,772,489 \\
8 & SA3-T2 & Rp7,483,713 \\
9 & SA3-T3 & Rp8,202,751 \\
\hline
\end{tabular}

Berikut penjelasan penyesuaian yang telah dilakukan, antara lain:

1) Penyesuaian Jenis Data

Pada penelitian ini, untuk informasi transaksi harga jual beli diberikan persentase $0 \%$ karena merupakan harga yang dipakai pada saat transaksi. Untuk informasi harga penawaran diberikan persentase (-5\%) hingga $(-10 \%)$ karena harga pada saat proses penawaran, harga tanah yang ditawarkan masih bisa dikurangi hingga estimasi maksimal 10\%.

2) Penyesuaian Waktu

Pada tahap ini data-data informasi harga tanah disesuaikan menurut waktu transaksi dari informasi harga tanah. Penyesuaiannya dilakukan dengan menambahkan kalibrasi persentase waktu dimana pada penelitian ini dihitung per tanggal 31 April 2016. Rata-rata penambahan persentase waktu dari standar yang ada ialah $1 \%$ per bulan.

3) Penyesuaian Sumber Data

Untuk informasi yang didapatkan dari pemilik diberikan persentase $0 \%$, untuk developer dan broker diberikan persentase (-2\%) hingga (-1\%) karena untuk pihak marketing akan mengambil keuntungan tidak lebih dari $2 \%$. Untuk informasi dari warga diberikan persentase $(-5 \%)$ hingga $5 \%$.

4) Penyesuaian Jenis Penggunaan

Jenis penggunaan tanah untuk rumah diberikan persentase $0 \%$ dan jenis penggunaan tanah yang memiliki nilai komersial seperti kos-kosan, ruko, dan lain-lain akan diberikan persentase (-10\%) hingga (-50\%).

5) Penyesuaian Kontur

Pada kota Surabaya, diasumsikan mempunyai ketinggian kontur yang tidak terlalu signifikan, diberikan persentase $0 \%$ yang artinya tidak perlu dilakukan penyesuaian.

6) Penyesuaian Elevasi Terhadap Jalan

Lahan yang tingginya sama atau proporsional terhadap tinggi jalan secara otomatis lahan tersebut akan lebih baik jika dibandingkan dengan lahan yang terlalu rendah atau terlalu tinggi terhadap ketinggian jalan. Untuk penyesuaian elevasi terhadap jalan diberikan persentase $(-2 \%)$ untuk penambahan biaya urukan tanah untuk penambahan elevasi.

7) Penyesuaian Bentuk Bidang

Pada penelitian ini, bentuk bidang yang ditemukan tidak terdapat perbedaan yang signifikan sehingga diberikan persentase $0 \%$ yang artinya tidak diperlukkan penyesuaian.

8) Penyesuaian Keluasan

Setiap lahan tanah biasanya akan berbeda dari segi luasnya, jika suatu lahan ditawarkan tentunya lahan yang lebih besar 
luasnya akan lebih murah dibanding dengan lahan yang luasnya lebih kecil karena itu keluasan lahan menjadi faktor penyesuaian dengan menambah atau mengurangi persentase antara data acuan dan data pembanding. Untuk lahan yang luasnya lebih dari $500 \mathrm{~m} 2$ diberikan penambahan persentase sebesar $5 \%$.

9) Penyesuaian Kedudukan Tanah

Pada penelitian ini, untuk lahan yang terletak di pinggir jalan arteri akan diberikan penambahan persentase sebesar 5\% hingga 50\% sesuai dengan kondisi di lapangan.

10) Penyesuaian Jenis Hak Tanah

Untuk lahan yang mempunyai status tanah selain Sertifikat Hak Milik (SHM) diberikan penambahan persentase sebesar $5 \%$ hingga $10 \%$.

\section{Hasil Deliniasi Zona Baru}

Data hasil perhitungan nilai tanah yang telah dilakukan proses penyesuaian di-plot pada peta kerja yang berisikan batas zona dengan metode von thunen, ternyata deliniasi zona tersebut tidak sesuai dengan prinsip pembuatan batas imajiner ZNT pada Surat Edaran Direktur Jenderal Pajak nomor SE25/PJ.6/2006. Maka diperlukan pembuatan batas imajiner zona baru dari hasil data nilai tanah berdasarkan peraturan tersebut.

Hasil deliniasi zona baru pada daerah sekitar CBD SIER terdiri dari 33 zona, yang terdiri dari 25 zona lahan pemukiman dan perumahan dan 8 zona kawasan industri yang lokasinya tersebar seperti pada Gambar 3.

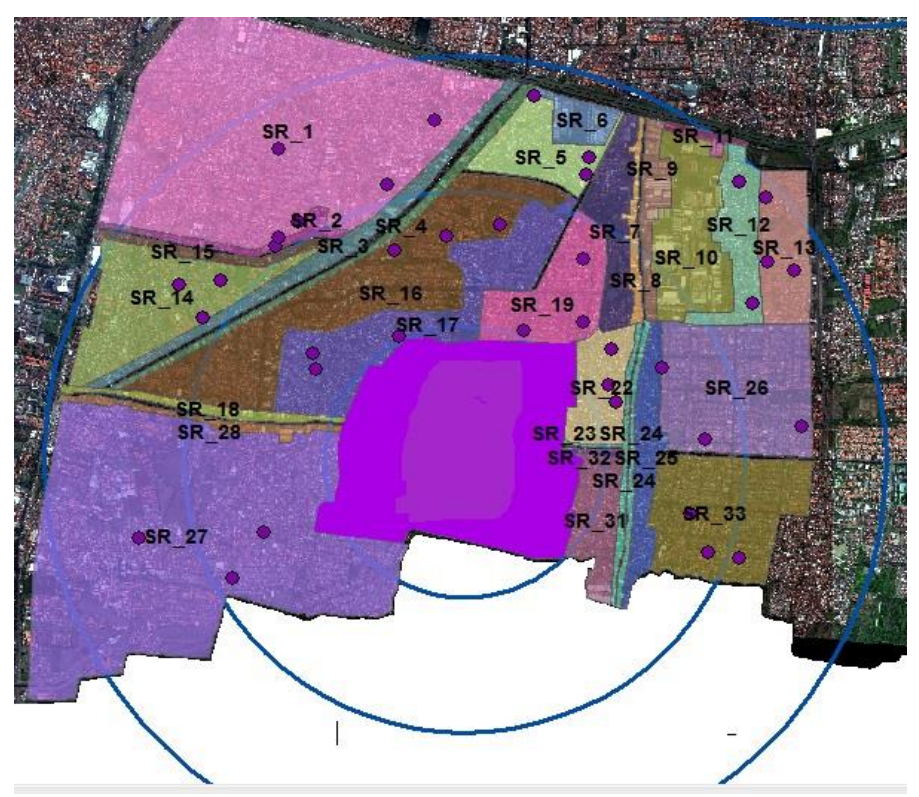

Gambar 3. Hasil deliniasi Zona Baru daerah sekitar CBD SIER.

(Sumber : Hasil Pengolahan Data)

\section{Perhitungan Nilai Indikasi Rata-Rata (NIR)}

1) Perhitungan NIR Setiap Zona

Nilai Indikasi Rata-Rata (NIR) adalah Nilai rata-rata yang diperoleh dari Analisis Zona Nilai Tanah (ZNT) pada data-data yang telah melalui proses penyesuaian dimana terdapat minimal 3 data informasi harga tanah/data pembanding pada satu lokasi ZNT. Penentuan NIR dilakukan dengan cara menjumlahkan minimal 3 data tersebut pada setiap zona dan diambil rata-rata sehingga mendapatkan Nilai Indikasi Rata-Rata (NIR).

Pada daerah sekitar CBD SIER, terdapat 35 Zona Nilai Tanah yang akan dihitung Indikasi Nilai Tanahnya. Terdapat 23 zona yang memiliki data Informasi Harga Tanah dan 12 Zona tidak memiliki Informasi Harga Tanah. Beberapa hasil dari perhitungan NIR dapat dilihat pada Tabel 2.

Tabel 2.

Hasil Perhitungan NIR setiap zona pada daerah sekitar CBD SIER

\begin{tabular}{ccccc}
\hline No & $\begin{array}{c}\text { Kode } \\
\text { Titik }\end{array}$ & $\begin{array}{c}\text { Kode } \\
\text { Zona }\end{array}$ & $\begin{array}{c}\text { Indikasi Nilai } \\
\text { Pasar Tanah / }{ }^{2}\end{array}$ & $\begin{array}{c}\text { Nilai Indikasi } \\
\text { Rata-Rata } \\
\text { (NIR) Tanah } \\
/ \mathrm{m}^{2}\end{array}$ \\
\hline 1 & SA3-T4 & & $\mathrm{Rp} 9,188,538$ & \\
2 & SH3b-T5 & SR-1 & Rp7,064,557 & Rp7,645,354 \\
3 & SA3-T6 & & Rp6,682,967 & \\
4 & SH3b-T2 & & Rp11,536,850 & \\
5 & SH3b-T1 & SR-2 & Rp11,794,474 & Rp11,708,599 \\
6 & SH3b-T3 & & Rp11,794,474 & \\
7 & SA3-T1 & & Rp6,772,489 & \\
8 & SA3-T2 & SR-5 & Rp7,483,713 & Rp7,486,318 \\
9 & SA3-T3 & & Rp8,202,751 & \\
\hline \hline
\end{tabular}

2) Perhitungan NIR dari NIR Zona Lain

Setelah dilakukan penilaian yang memakai Analisis Penentuan Nilai Indikasi Rata-Rata (NIR), maka untuk ZNT yang tidak memiliki data harga jual, penentuan NIR dilakukan dengan cara menentukan nilai objek acuan dengan dari data harga jual ZNT lain yang terdekat. Analisis penentuan Nilai Indikasi Rata-Rata (NIR) dari Zona Lain dilakukan dengan memakai data pembanding dari zona yang ada, data yang pakai sebagai pembanding minimal 3 zona (ZNT). Beberapa hasil dari perhitungan NIR dari NIR Zona Lain dapat dilihat pada Tabel 3.

Tabel 3.

Hasil Perhitungan NIR dari NIR zona lain pada daerah sekitar CBD SIER

\begin{tabular}{cccc}
\hline No & $\begin{array}{c}\text { Kode } \\
\text { Zona }\end{array}$ & Zona Pembanding & $\begin{array}{c}\text { NIR Hasil } \\
\text { Perbandingan } \\
/ \mathrm{m}^{2}\end{array}$ \\
\hline 1 & & SR_1 & \\
2 & SR_3 & SR_2 & Rp11,732,292 \\
3 & & SR_15 & \\
4 & & SR_3 & \\
5 & SR_4 & SR_2 & Rp11,136,631 \\
6 & & SR_16 & \\
7 & & SR_5 & \\
8 & SR_7 & SR_19 & Rp7,518,484 \\
9 & & SR-12 & \\
\hline \hline
\end{tabular}


Adapun penyesuaian dalam analisis penentuan Nilai Indikasi Rata-Rata (NIR) dengan zona lain adalah:

a) Penyesuaian Lokasi

Secara umum antara lokasi zona satu dengan zona yang lainnya berbeda, dimana potensi strategis tempat lokasi sangat dominan dalam menentukan besarnya penyesuaian. Pengaruh lokasi pada penelitian ini dipengaruhi oleh kedudukan zona terhadap jalan arteri primer dan arteri sekunder yang mempunyai dominasi paling besar. Penyesuaian lokasi dilakukan dengan memberikan nilai prosentasi sebesar $(-5 \%)$ hingga 50\% sesuai dengan kondisi di lapangan.

b) Penyesuaian Fisik

Pada penelitian ini kondisi fisik dipresentasikan dengan kondisi kontur, pada lokasi penelitian ini mempunyai ketinggian kontur yang tidak terlalu signifikan, diberikan persentase $0 \%$ yang artinya tidak perlu dilakukan penyesuaian. c) Penyesuaian Jenis Penggunaan

Penyesuaian jenis penggunaan dilakukan dengan memberikan nilai prosentasi sebesar (-5\%) hingga $15 \%$ sesuai dengan kondisi di lapangan.

\section{E. Hasil Peta Klasifikasi Nilai Tanah daerah sekitar CBD}

Peta Klasifikasi Nilai Tanah merupakan peta tematik yang menggambarkan besaran nilai tanah pada wilayah tertentu. Hasil peta ini memudahkan analisis pengaruh CBD terhadap nilai tanah di daerah sekitarnya berdasarkan analisis klasifikasi NIR tanahnya. Hasil Peta Klasifikasi Nilai Tanah daerah sekitar CBD dapat dilihat pada Gambar 4.
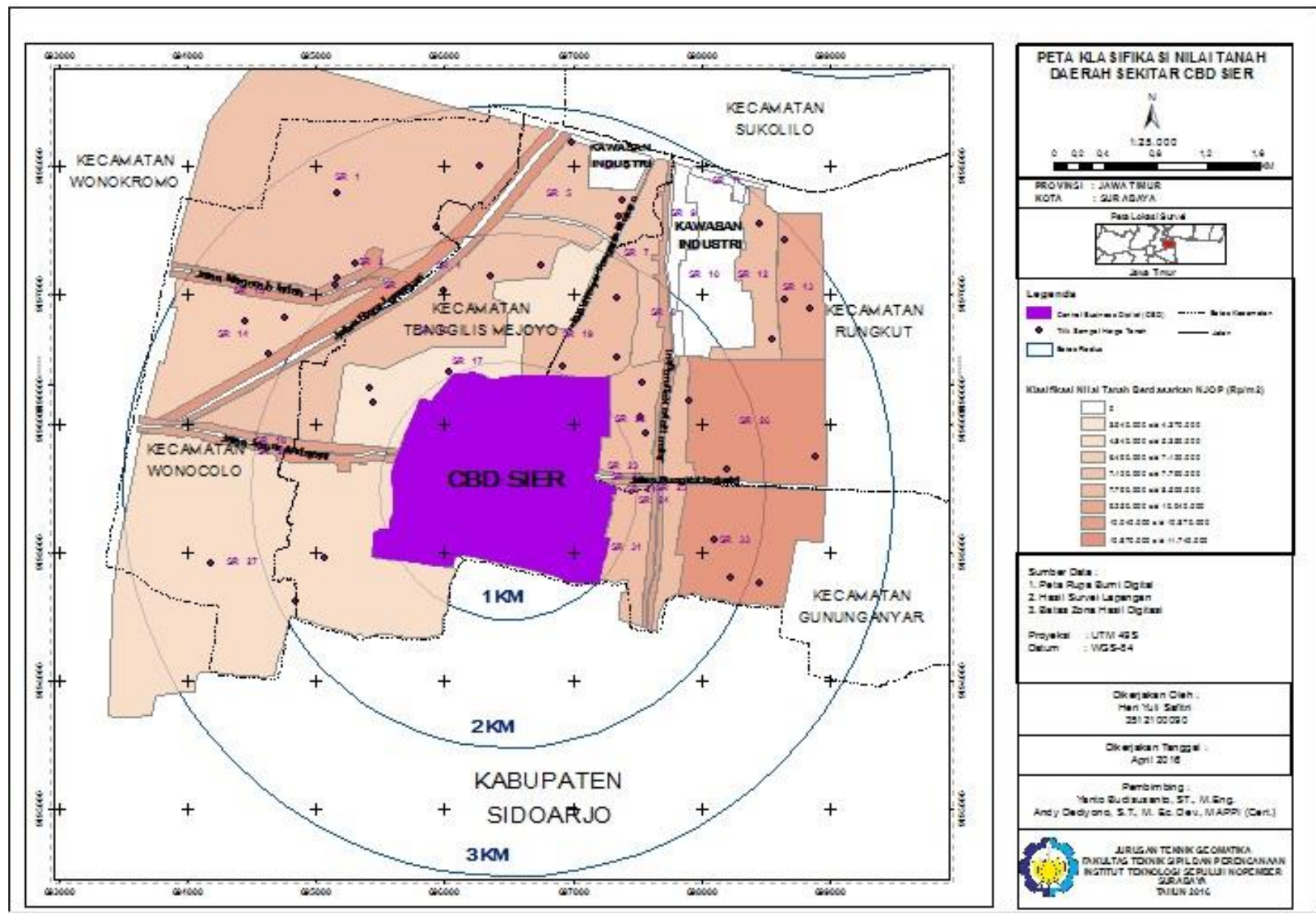

Gambar 4. Hasil Peta Klasifikasi Nilai Tanah daerah sekitar CBD SIER.

(Sumber : Hasil Pengolahan Data)

\section{KESIMPULAN DAN SARAN}

\section{A. Kesimpulan}

Adapun beberapa hal yang bisa disimpulkan dari penelitian ini adalah :

1. Pembuatan zona nilai tanah pada daerah sekitar CBD SIER terdiri dari 33 zona, yang terdiri dari 35 zona lahan pemukiman dan perumahan dan 8 zona kawasan industri.

2. Hasil analisis klasifikasi NIR pada daerah sekitar CBD SIER yang dilakukan sejauh 3 kilometer mempunyai kecenderungan nilai tanah yang semakin tinggi jika menjauh dari CBD. NIR tertinggi terletak pada radius 3 kilometer yaitu sebesar $\mathrm{Rp} 11.732 .291,-/ \mathrm{m}^{2}$, zona ini memiliki jarak yang cukup jauh terhadap CBD. Hal ini ditunjukan dengan persentase pada radius 3 kilometer sebesar $(-25 \%)$ terhadap NIR rata-rata pada radius 2 kilometer. Hasil persentase yang menunjukan angka negatif menunjukan bahwa NIR pada radius 2 kilometer memiliki nilai yang lebih rendah dibandingkan dengan NIR pada radius 3 kilometer. Hal ini disebabkan oleh lokasi yang sangat berdekatan dengan daerah industri tersebut menimbulkan potensi mengalami dampak kebisingan serta dampak limbah industri. Selain faktor 
jarak terhadap CBD SIER, faktor kedudukan tanah terhadap jalan juga sangat mempengaruhi nilai tanah tersebut.

\section{B. Saran}

Dalam pengelompokan bidang tanah dalam satu Zona Nilai Tanah dengan mempertimbangkan kriteria yang telah ditentukan berdasarkan Surat Edaran Direktur Jenderal Pajak Nomor: SE-25/PJ.6/2006 tentang Tata Cara Pembentukan/Penyempurnaan ZNT/NIR, agar dapat menghasilkan zona yang lebih akurat.

\section{DAFTAR PUSTAKA}

[1] Adi, N.S. 2015. "Analisa Zona Nilai Tanah Akibat Perubahan Penggunaan Lahan (Studi Kasus : Surabaya Timur”. Surabaya: Program Studi Teknik Geomatika FTSP-ITS.

[2] Hidayati, W., \& Harjanto, B. (2001). Konsep Dasar Penilaian Properti. Yogyakarta: BPFE-YOGYAKARTA.

[3] Hermit, H. (2009). Teknik Penaksiran Harga Tanah Perkotaan. Bandung: CV. Mandar Maju.

[4] DEPKEU RI, Dirjen Pajak No. SE-25/PJ.6/2006 tentang Tata cara Pembentukan/Penyempurnaan ZNT/NIR. 